\title{
Transcatheter aortic valve replacement guidelines for community medicine physicians
}

\author{
Juan A Siordia ${ }^{1 *}$ and Sreekumar Subramanian ${ }^{2}$ \\ ${ }^{1}$ Department of Surgery, University of Arizona Medical Center, University of Arizona, 1501 N Campbell Ave, Tucson, AZ, USA \\ ${ }^{2}$ TriStar Cardiovascular Surgery, TriStar Centennial Medical Center (HCA), 2400 Patterson St, Nashville, TN, USA
}

\begin{abstract}
Transcatheter Aortic Valve Replacement is a decade-old approach for replacing stenotic aortic valves in high-risk patients. Since the PARTNER trial, further advances and improvements in technology and technique have occurred. The evaluation and advantages are well-known among cardiovascular physicians, but are not as well-understood among internists and community physicians. The following review serves as a summary for the key points for physicians practicing community medicine.
\end{abstract}

\section{Introduction}

Transcatheter Aortic Valve Replacement (TAVR) is a novel approach for replacing the aortic valve in patients that are deemed high-risk for surgical aortic valve replacement. In November 2011, the FDA approved the use of the TAVR valve via the trans-femoral installation approach for patients that were considered inoperable [1]. In October 2012, the pool of patients increased to allow those deemed high-risk for surgical intervention. Currently, TAVR is offered to those that are high-risk for conventional aortic valve replacement or those who have been evaluated independently by two surgeons as inoperable [2].

TAVR patients are typically those that are deemed inoperable or too high-risk for traditional aortic valve replacement surgery. However, with recent advances, operative mortality and complication rates have diminished. Thirty-day mortality after TAVR has decreased to $4.5 \%$. The combined rate of death, vascular complications, myocardial infarction, and stroke was 9\% [3]. Ischemic strokes, the main postprocedural complication, have now decreased to a $1.5-2.4 \%$ rate $[3,4]$.

\section{Benefits of TAVR}

The promising benefits of TAVR have been recognized since the completion of the PARTNER trial [4]. Patients may still refuse surgical or catheter intervention due to personal reasons. Autonomy must be upheld in medical practice along with beneficence. One-year survival for patients with untreated severe aortic stenosis is 69\%, compared to 94\% with operated individuals [5]. Patients should still be referred to cardiologists to perform other interventions or even medical therapy. Beta-blocker and statin usage prolong the rate of mortality (relative risk 0.52 for each therapy; $\mathrm{p}=0.02$ for beta-blockers and $\mathrm{p}=0.05$ for statins) [6]. With the improvement of a 10 -french catheter (from a 14-french), balloon aortic valvulopathy confers promising acute outcomes. However, long-term outcomes are only favorable if used as a bridge to surgical or TAVR intervention [7].

\section{Usage of balloon valvuloplasty}

Balloon valvuloplasty was introduced in 1985 with the intent to replace the need of aortic valve replacement in high-risk patients. The procedure itself produced useful acute results after operations. In a 20022005 study with 141 patients, 6 patients (4\%) died and 9 patients (6\%) suffered acute post-operative complications including strokes (2), nonsurgical vascular complications (8), and $3^{\text {rd }}$ degree heart block (5) [8]. Today, with a smaller 10 -french catheter, post-operative complications have decreased. This improved technique makes it feasible for highrisk patients to acquire balloon valvuloplasty as a means of bridging to surgical aortic valve replacement or TAVR. Patients that benefit from this bridge approach include those with chronic obstructive pulmonary disease and chronic kidney disease; the mean logistic euroSCORE is $28.7(\mathrm{p}<0.5)$. One study showed that at 20 months, $26.3 \%$ of patients are successfully bridged to surgical or TAVR therapy. 5-year mortality rate was $22 \%$ for the bridge-to-TAVR group, which was significant compared to the $3.3 \%$ seen in the medically-managed group (including those that acquired balloon aortic valvuloplasty alone) [7].

Balloon aortic valvuloplasty can serve as acute palliative treatment for when surgery and TAVR are contraindicated [9]. This can improve aortic stenosis symptoms while assessment and discussion occurs as to whether TAVR will deliver a benefit for the patient. Valvuloplasty may also help in the decision process by assessing improvement in left-ventricular ejection fraction, pulmonary hypertension, and mitral regurgitation; this can discern whether the patient would benefit from either TAVR or palliative care.

\section{Evaluation for TAVR}

When aortic stenosis is suspected and diagnosed, the next step is to determine the best therapeutic intervention for the patient. According

Correspondence to: Juan A Siordia, Department of Surgery, University of Arizona Medical Center, University of Arizona, 1501 N Campbell Ave, Tucson, AZ, USA, Tel: (520) 223-5713; E-mail: jas@email.arizona.edu

Key words: TAVR, aortic atenosis, guidelines, PARTNER trial

Received: July 05, 2015; Accepted: August 07, 2015; Published: August 10, 2015 
to the 2014 guidelines for aortic stenosis, severe symptomatic aortic valve replacement requires immediate intervention. In asymptomatic cases, qualification via stress testing and imaging is mandated [10].

Stress testing helps quantify the severity of aortic stenosis and can aid in determining the probable outcomes after replacement. The dobutamine stress test with echocardiography has shown reliability in calculating the outcomes of patients prior to intervention. Most patients that have severe aortic stenosis present New York Heart Association Class III/VI heart failure and have low left-ventricular ejection fraction. Determining the cardiac reserve of the patient with the dobutamine stress test can confer a prediction as to whether mortality during aortic valve replacement will be significant [11-13]. Cardiac reserve is suggested with a $>20 \%$ ejection fraction increase after dobutamine infusion. Patients that present with cardiac reserve have a $5 \%$ perioperative mortality, as opposed to $22-32 \%$ in those lacking of cardiac reserve $[12,14]$. Nevertheless, 5 -year survival is significantly higher in patients that received aortic valve replacement despite a low cardiac reserve compared to those that were managed medically ( $54 \%$ vs $13 \%, \mathrm{p}=0.001$ ) [14].

Other diagnostic tests can also aid in determining the prognosis of patients with severe aortic stenosis. During exercise stress testing, checking Brain-Natriuretic Peptide (BNP) levels also confers a prognosis in regards to perioperative mortality [15]. Information presented in an exercise stress test echocardiogram can also effectively reveal the operative mortality of patients [16]. Options to determine the outcome of aortic stenosis cases exist, but costs and effectiveness should be considered when employing tests.

A concern with asymptomatic patients is whether they are truly asymptomatic. Some patients have been accustomed to the chronic symptoms of aortic stenosis that they do not realize it is part of the pathology. Other patients actually become symptomatic after stress testing [16-18]. A meta-analysis proposes that the prognosis of severe aortic stenosis can easily be depicted with the use of stress testing. Symptoms arising during the examination correlate with severe outcomes if left untreated [19]. Measuring the aortic valve size for patients with aortic stenosis independently determines survival and heart failure, even if the patient has a low ejection fraction or asymptomatic [20]. Therefore, the decision for referral to surgery should be based on the results of stress testing and imaging rather than history and clinical presentation.

Patients that typically undergo TAVR include those that have many comorbidities, including hypertension, diabetes, chronic obstructive pulmonary disease, and chronic kidney disease in addition to aortic stenosis-related complications, especially New York Heart Association Class III/VI heart failure [7]. With frailty being high among these patients, risk stratification is performed among surgeons in order to determine the mortality probability. One particular risk calculator extensively used in the Society of Thoracic Surgeons (STS) Predicted Risk of Mortality score. However, current risk score calculators prove suboptimal in predicting severe aortic stenosis and TAVR operations. In terms of severe aortic stenosis, the STS score is only successful in predicting the long-term mortality rate of patients after surgical aortic valve replacement [21]. TAVR predictive mortality with STS score is much more suboptimal. The calculator underestimates the mortality risk of patients that undergo the percutaneous aortic valve implantation [22]. Nevertheless, physicians are highly encouraged to use the STS risk score calculator for every patient presenting with aortic stenosis $[21,22]$.

\section{Advantages of TAVR}

Transfermoral TAVR is the first FDA-approved approach for TAVR. It is the most common route undertaken in order reach the aortic valve via catheter. Due to recent advances, the approach has overcome the preclusion presented by certain comorbidities [1]. Furthermore, transfemoral TAVR can be performed under local anesthesia. Local anesthesia presents with perioperative hemostability and less length of hospital stay. The method also facilitates recovery in frail and elderly patients with problems including chronic renal failure and pulmonary hypertension [23]. With further advances, TAVR will present with less complications.

Before the introduction of TAVR, high-risk patients were treated with medical management. Unfortunately, the outcomes of this treatment were grim. With the introduction of percutaneous aortic valve implantation, medical; social; and ethical issues are easily handled. Medical management with the addition of TAVR has drastically improved outcomes [24-26]. Ethical concerns and interventional management are performed in a team approach with cardiac surgeons, interventional cardiologists, cardiac imaging specialists, anesthesiologists, geriatricians, and specialized nursing staff [27].

\section{Valve-in-Valve approach}

Bioprosthetic valves have a life-span average of about 5 years. Re-intervention is required if the valve degenerates, produces aortic insufficiency, or has a calcification buildup with resultant bioprosthetic stenosis. Implanting a valve into a previously implanted bioprosthetic valve can be performed via TAVI; this is known as the valve-in-valve approach. Placement of a second or even a third transcatheter valve is possible, although occurring at a small rate of $1.8 \%$ of surgical interventions [28]. In the PARTNER trial, 7 of 348 (2\%) patients required the valve-in-valve approach due to embolization (2 patients) and residual aortic regurgitation (5 patients) [29]. Currently, valvein-valve success is $87-96 \%$ with TAVR; 30 -day mortality is recorded at $7.8 \%$ [30]. With further advances, this procedure can be performed to prolong the survival of high-risk patients that are deemed high-risk for a mechanical aortic valve replacement via the traditional surgical approach [31].

\section{Future directions of TAVR}

Long-term durability for TAVR requires further research. The first TAVR operation was described in 2002 [32]. This limits the amount of studies that could have been conducted in terms of longterm outcomes. One study using the Italian CoreValve registry found that 3-year post-operative outcomes did not differ from 1-year postoperative outcomes. Furthermore, aortic insufficiency did not arise in patients that did not present with in the acute post-operative stage [33]. However, this only slightly reveals the durability of the TAVR valve.

Another concept is the implementation in lower-risk patients. Patients that undergo the TAVR have a high-risk profile calculated by the Society of Thoracic Surgery (STS) mortality score calculator. The population that undergoes TAVR have an STS score of around $14.0 \pm$ $11.8 \%$ [34]. However, some of the contributing factors of the high-risk profile are from the diseased aortic valve itself. Potentially, removing some of the factors that will quickly be ameliorated with the insertion of the new valve will lower the true mortality risk of some patients [26]. Nevertheless, investigation is still required in those that are already at a low STS mortality score. A moderate study of 420 patients from Munich with low STS mortality scores at around 4.8\%-7.1\% showed a promising 30 -day mortality outcome of $3.8 \%$ and a 6 -month mortality 
of $12.4 \%$ [29]. More information is nevertheless demanded for these types of patients if it is to be used as a standard protocol for any patient with severe aortic stenosis.

Further information is required for determining the long-term outcomes of the TAVR operation. This lack of knowledge is what hinders the use of the operation in the younger population. Normally, the high-risk patients frequently present at late ages; different outcomes may occur with younger patients with severe aortic stenosis. The PARTNER II trial should presents results concerning the outcomes of younger TAVR individuals in the near future [35].

\section{References}

1. Webb JG, Wood DA (2012) Current status of transcatheter aortic valve replacement. $J$ Am Coll Cardiol 60: 483-492. [Crossref]

2. Tang GH, Lansman SL, Cohen M, Spielvogel D, Cuomo L, et al. (2013) Transcatheter aortic valve replacement: current developments, ongoing issues, future outlook. Cardiol Rev 21: 55-76. [Crossref]

3. Muñoz-García AJ, Hernández-García JM, Jiménez-Navarro MF, Alonso-Briales JH, Domínguez-Franco AJ, et al. (2012) Survival and predictive factors of mortality after 30 days in patients treated with percutaneous implantation of the CoreValve aortic prosthesis. Am Heart J 163: 288-294. [Crossref]

4. Smith CR, Leon MB, Mack MJ, Miller DC, Moses JW, et al. (2011) Transcatheter versus surgical aortic-valve replacement in high-risk patients. N Engl J Med 364: 2187 2198. [Crossref]

5. Bach DS (2011) Prevalence and characteristics of unoperated patients with severe aortic stenosis. J Heart Valve Dis 20: 284-291. [Crossref]

6. Pai RG, Kapoor N, Bansal RC, Varadarajan P (2006) Malignant natural history of asymptomatic severe aortic stenosis: benefit of aortic valve replacement. Ann Thorac Surg 82: 2116-2122. [Crossref]

7. Eltchaninoff H, Durand E, Borz B, Furuta A, Bejar K, et al. (2014) Balloon aortic valvuloplasty in the era of transcatheter aortic valve replacement: acute and long-term outcomes. Am Heart J 167: 235-240.

8. Agatiello C, Eltchaninoff H, Tron C, Bauer F, Babaliaros V, et al. (2006) [Balloon aortic valvuloplasty in the adult. Immediate results and in-hospital complications in the latest series of 141 consecutive patients at the University Hospital of Rouen (20022005)]. Arch Mal Coeur Vaiss 99: 195-200. [Crossref]

9. Vahanian A, Alfieri O, Andreotti F, Antunes MJ, Barón-Esquivias G, et al. (2012) Guidelines on the management of valvular heart disease (version 2012): the Joint Task Force on the Management of Valvular Heart Disease of the European Society of Cardiology (ESC) and the European Association for Cardio-Thoracic Surgery (EACTS). Eur J Cardiothorac Surg 42: S1-44. [Crossref]

10. Nishimura RA, Otto CM, Bono RO, Carabello BA, Erwin JP, et al. (2014) 2014 AHA ACC guidelines for the management of patients with valvular heart disease: a report of the American college of cardiology/American heart association task force on practice guidelines. J Am Coll Cardiol 63: 57-185.

11. Monin JL, Monchi M, Gest V, Duval-Moulin AM, Dubois-Rande JL, et al. (2001) Aortic stenosis with severe left ventricular dysfunction and low transvalvular pressure gradients: risk stratification by low-dose dobutamine echocardiography. $\mathrm{J}$ Am Coll Cardiol 37: 2101-2107. [Crossref]

12. Monin JL, Quéré JP, Monchi M, Petit H, Baleynaud S, et al. (2003) Low-gradient aortic stenosis: operative risk stratification and predictors for long-term outcome: a multicenter study using dobutamine stress hemodynamics. Circulation 108: 319-324. [Crossref]

13. Nishimura RA, Grantham JA, Connolly HM, Schaff HV, Higano ST, et al. (2002) Low-output, low-gradient aortic stenosis in patients with depressed left ventricular systolic function: the clinical utility of the dobutamine challenge in the catheterization laboratory. Circulation 106: 809-813. [Crossref]

14. Tribouilloy C, Lévy F, Rusinaru D, Guéret P, Petit-Eisenmann H, Baleynaud S, et al. (2009) Outcome after aortic valve replacement for low-flow/low-gradient aortic stenosis without contractile reserve on dobutamine stress echocardiography. $J$ Am Coll Cardiol 53: 1865-1873. [Crossref]

15. Capoulade R, Magne J, Dulgheru R, Hachicha Z, Dumesnil JG, et al. (2014) Prognostic value of plasma B-type natriuretic peptide levels after exercise in patients with severe asymptomatic aortic stenosis. Heart 100: 1606-1612. [Crossref]
16. Lancellotti P, Lebois F, Simon M, Tombeux C, Chauvel C, et al. (2005) Prognostic importance of quantitative exercise doppler echocardiography in asymptomatic valvular aortic stenosis. Circulation 112: 377-382.

17. Amato M, Moffa P, Werner K, Ramires J (2001) Treatment decision in asymptomatic aortic valve stenosis: role of exercise testing. Heart 86: 381-386. [Crossref]

18. Das P, Rimington H, Chambers J (2005) Exercise testing to stratify risk in aortic stenosis. Eur Heart J 26: 1309-1313. [Crossref]

19. Rafique AM, Biner S, Ray I, Forrester JS, Tolstrup K, et al. (2009) Meta-analysis of prognostic value of stress testing in patients with asymptomatic severe aortic stenosis. Am J Cardiol 104: 972-977. [Crossref]

20. Malouf J, Le Tourneau T, Pellikka P, Sundt TM, Scott C, et al. (2012) Aortic valve stenosis in community medical practice: determinants of outcome and implications for aortic valve replacement. J Thorac Cardiovasc Surg 144: 1421-1427. [Crossref]

21. Le Tourneau T, Pellikka PA, Brown ML, Malouf JF, Mahoney DW, et al. (2010) Clinical outcome of asymptomatic severe aortic stenosis with medical and surgical management: importance of STS score at diagnosis. Ann Thorac Surg 90: 1876-1883. [Crossref]

22. Piazza N, Wenaweser P, van Gameren M, Pilgrim T, Tzikas A, et al. (2010) Relationship between the logistic EuroSCORE and the Society of Thoracic Surgeons Predicted Risk of Mortality score in patients implanted with the CoreValveReValving system--a BernRotterdam Study. Am Heart J 159: 323-329. [Crossref]

23. Motloch LJ, Rottlaender D, Reda S, Larbig R, Bruns M, et al. (2012) Local versus general anesthesia for transfemoral aortic valve implantation. Clin Res Cardiol 101: 45-53. [Crossref]

24. Faxon D (2011)Transcatheter Aortic Valve Implantation: Coming of Age. Circulation 124: 439-440.

25. Leon MB, Smith CR, Mack M, Miller DC, Moses JW, et al. (2010) Transcatheter aortic-valve implantation for aortic stenosis in patients who cannot undergo surgery. $N$ Engl J Med 363: 1597-1607. [Crossref]

26. Carabello B (2012) The placement of aortic transcatheter valve (PARTNER) trial: the view of a cardiologist. Circulation 125: 3240-3242. [Crossref]

27. Stortecky S, Buellesfeld L, Wenaweser P, Windecker S (2012) Transcatheter aortic valve implantation: prevention and management of complications. Heart 96: 52-64.

28. Genereux P, Head S, Van Mieghem N, Kodali S, Kirtane AJ, et al. (2012) Clinica outcomes after transcatheter aortic valve replacement using valve academic research consortium definitions: a weighted meta-analysis of 3519 patients from 16 studies. $J$ Am Coll Cardiol 59: 2317-2326. [Crossref]

29. Mack M (2012) Transcatheter aortic valve implantation: changing patient populations and novel indications. Heart 98: 73-79.

30. Dvir D, Webb J, Brecker S, Bleiziffer S, Hildick-Smith D, et al. (2012) Transcatheter aortic valve replacement for degenerative bioprosthetic surgical valves: results from the global valve-in-valve registry. Circulation 126: 2335-2344. [Crossref]

31. Webb JG, Wood DA, Ye J, Gurvitch R, Masson JB, et al. (2010) Transcatheter valvein-valve implantation for failed bioprosthetic heart valves. Circulation 121: 1848-1857. [Crossref]

32. Bourantas C, Serruys P (2014) Evolution of transcatheter aortic valve replacement. Circ Res 114: 1037-1051. [Crossref]

33. Ussia GP, Barbanti M, Petronio AS, Tarantini G, Ettori F, et al. (2012) Transcatheter aortic valve implantation: 3 -year outcomes of self-expanding CoreValve prosthesis. Eur Heart J 33: 969-976. [Crossref]

34. Unbehaun A, Pasic M, Drews T, Penkalla A, Dreysse S, et al. (2014) Transapical aortic valve implantation: predictors of survival up to 5 years in 730 patients: an update. Eur J Cardiothorac Surg 10: 1093. [Crossref]

35. Guyton RA (2012) The placement of aortic transcathter valve (PARTNER) trial: the surgeon's perspective: celebration and concern. Circulation 125: 3237-3239. [Crossref]

Copyright: (C2015 Siordia JA. This is an open-access article distributed under the terms of the Creative Commons Attribution License, which permits unrestricted use, distribution, and reproduction in any medium, provided the original author and source are credited. 